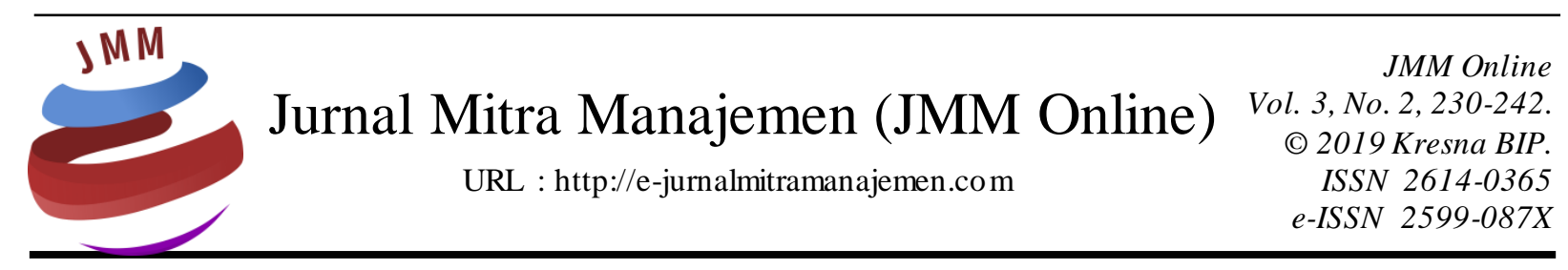

\title{
PENGARUH KOMUNIKASI INTERPERSONAL DAN KEPERCAYAAN GURU TERHADAP PRODUKTIVITAS KERJA GURU SEKOLAH DASAR DI KOTA TOMOHON
}

\author{
Maxie A.J. Liando \\ Universitas Negeri Manado
}

INFORMASI ARTIKEL

Dikirim : 19 Februari 2019

Revisi pertama : 22 Februari 2019

Diterima : 25 Februari 2019

Tersedia online : 04 Maret 2019

Kata Kunci : Produktivitas Kerja, Komunikasi Interpersonal,

Kepercayaan Guru

Email : maxieliando@unima.ac.id

\section{ABSTRAK}

Penelitian ini bertujuan untuk mengetahui produktivitas kerja guru sekolah dasar di Kota Tomohon. Tujuan penelitian untuk mengkaji dan mendeskripsikan hasil analisis dan interpretasi tentang komunikasi interpersonal dan kepercayaan guru terhadap produktivitas kerja guru sekolah dasar. Menggunakan metode penelitian kuantitatifdengan teknik sampling yang diambil secara random. Pengumpulan data menggunakan instrumen penelitian dengan analisis korelasi dan regresi. Hasil analisis data membuktikan bahwa: Terdapat hubungan yang berarti antara komunikasi interpersonal dan kepercayaan guru dengan produktivitas kerja guru sekolah dasar di kota Tomohon. Arah hubungan positif, besar hubungan 0,578 atau sekitar 33,4\% produktivitas kerja guru sekolah dasar ditentukan secara simultan oleh variabel komunikasi interpesersonal dan kepercayaan guru. Demikian signifikannya kontribusi tersebut tentu akan berdampak besar pada produktivitas kerja guru. Karena itu disarankan agar pimpinan sekolah dan intan si terkait melakukan perbaikan, baik menyangkut kominikasi interpersonal gurunya maupun menyangkut kepercayaan guru. 


\section{PENDAHULUAN \\ Latar Belakang}

Pendidikan merupakan kunci pembangunan untuk masa sekarang dan masa yang akan datang, karena melalui pendidikan diharapkan setiap individu dapat meningkatkan kualitasnya dalam bidang pendidikan. Salah satu unsur yang menunjang dan sekaligus terpenting dalam proses pendidikan adalah guru. Guru merupakan salah satu tenaga kependidikan yang mempunyai peran sebagai faktor penentu keberhasilan tujuan organisasi dan mutu pendidikan, karena guru yang langsung bersinggungan dengan peserta didik untuk memberikan bimbingan yang muaranya akan menghasilkan lulusan yang diharapkan.

Guru adalah kunci keberhasilan pendidikan, sebab inti dari kegiatan pendidikan adalah belajar mengajar yang memerlukan peran dari guru di dalamnya. Guru adalah profesi/jabatan atau pekerjaan yang memerlukan keahlian khusus sebagai guru. Dalam meraih mutu pendidikan yang baik sangat dipengaruhi oleh produktivitas kerja guru dalam melaksanakan tugasnya untuk mencapai keberhasilan pendidikan.

Produktivitas kerja guru berbeda dengan hasil produksi benda dan jasa yang mudah dihitung dan diukur. Produktivitas kerja guru dalam hal ini adalah bagaimana seorang guru melaksanakan pekerjaannya atau unjuk kerja. Produktivitas kerja menurut Tohardi dalam Edy Sutrisno $(2012 ; 100)$ adalah sikap mental yang selalu mencari perbaikan terhadap apa yang telah ada. Suatu keyakinan bahwa seseorang dapat melakukan pekerjaan lebih baik hari ini daripada hari kemarin dan hari esok lebih baik dari hari ini.

Secara umum mutu pendidikan yang baik menjadi tolok ukur bagi keberhasilan produktivitas kerja yang ditunjukkan guru. Sebagian besar waktu guru digunakan untuk bekerja, oleh karena itu aspek produktivitas kerja menjadi sorotan penting bagi profesi guru. Sementara faktor kepercayaan guru sangat berkaitan dengan upaya peningkatan produktivitas kerja guru.

Fenomena produktivitas kerja guru seperti yang diungkapkan diatas sifatnya umum dan hampir terjadi di seluruh wilayah Indonesia tidak terkecuali pada lingkup sekolah dasar negeri di kota Tomohon. Berdasarkan hasil wawancara yang dilakukan terhadap beberapa Kepala Sekolah dapat disimpulkan bahwa:

"Mayoritas guru sekolah dasar yang ada di kota Tomohon memiliki tingkat produktivitas rendah. Hal ini diukur dengan indikator pada kemampuannya membuat media pembelajaran inovatif yang sesuai dengan kebutuhan siswa di kelas, kurang termotivasi untuk mengikuti kegiatan-kegiatan penunjang tugas pokok seperti seminar, workshop, dan kegiatan pengembangan lainnya. Masih ada guru yang belum mendapat tunjangan sertifikasi karena belum memenuhi wajib mengajar yaitu 24 (dua puluh empat) jam mengajar dalam satu minggu".

Sumber data: Kepala Sekolah, November 2017.

Berdasarkan pengamatan di lapangan sebagian guru sekolah dasar di kota Tomohon masih menggunakan cara-cara lama dalam melakukan pembelajaran di kelas. Pendekatan pembelajaran yang digunakan di kelas masih didominasi oleh cara lama atau metode konvensional yang lebih mengutamakan metode ceramah dan miskin penggunaan metode-metode pembelajaran inovatif, kreatif dan inspiratif. 
Produktivitas kerja guru akan tercapai bilamana segala persyaratan yang dibutuhkan untuk menjadi seorang guru telah terpenuhi termasuk persyaratan kualifikasi akademik. Selain standar kualifikasi yang belum sepenuhnya terpenuhi, faktor lain yang menghambat kualitas kerja guru adalah adanya guru yang mengajar bukan pada bidang spesialisasinya artinya tidak sesuai antara latar belakang pendidikannya dengan mata pelajaran yang diampuhnya di sekolah, misalnya ada guru kelas yang berlatar belakang; Pendidikan Matematika, Pendidikan Bahasa Indonesia, Pendidikan Luar Sekolah dan yang lainnya. Sejatinya guru kelas harus berlatar belakang sarjana Pendidikan Guru Sekolah Dasar (PGSD). Kondisi yang seperti ini akan berpengaruh terhadap efektifitas proses pembelajaran di kelas sehingga secara tidak langsung akan menghambat guru dalam meningkatkan kualitas kerjanya.

\section{Rumusan Masalah}

Merujuk pada latarbelakang yang telah diuraikan sebelumnya, maka masalah dapat dirumuskan sebagai berikut:

1. Apakah terdapat pengaruh antara komunikasi interpersonal terhadap produktivitas kerja guru sekolah dasar di kota Tomohon?

2. Apakah terdapat pengaruh antara kepercayaan guru terhadap produktivitas kerja guru sekolah dasar di kota Tomohon?

3. Apakah terdapat pengaruh secara simultan antara komunikasi interpersonal dan kepercayaan guru terhadap produktivitas kerja guru sekolah dasar di kota Tomohon?

\section{Tujuan Penelitian}

Penelitian ini bertujuan untuk mengetahui produktivitas kerja guru sekolah dasar di Kota Tomohon. Secara khusus dapat dijabarkan tujuan penelitian sebagai berikut:

1. Untuk mengkaji dan mendeskripsikan hasil analisis dan interpretasi tentang pengaruh komunikasi interpersonal terhadap produktivitas kerja guru sekolah dasar.

2. Untuk mengkaji dan mendeskripsikan hasil analisis dan interpretasi tentang pengaruh kepercayaan guru terhadap produktivitas kerja guru sekolah dasar.

3. Untuk mengkaji dan mendeskripsikan hasil analisis dan interpretasi tentang komunikasi interpersonal dan kepercayaan guru terhadap produktivitas kerja guru sekolah dasar.

\section{Luaran Penelitian}

Luaran penelitian yang diharapkan adalah:

1. Hasil analisis dan interpretasi komunikasi interpersonal dan kepercayaan guru terhadap produktivitas kerja guru sekolah dasar di Kota Tomohon.

2. Artikel Ilmiah tentang hasil penelitian yang dimuat pada jurnal yang terakreditasi.

\section{KAJIAN PUSTAKA \\ Produktivitas Kerja}

Produktivitas pendidikan berbeda dengan hasil produksi benda atau jasa lain yang mudah dihitung atau diukur. Menurut Allan Thomas dalam Sedarmayanti (2009: 62) menyatakan bahwa salah satu cakupan produktivitas pendidikan adalah terkait 
dengan sikap dan kecakapan guru. Trivedi (2013:634) berpendapat bahwa prodiktivitas merupakan sebuah sistem yang dipakai untuk mengumpulkan ukuran kinerja, kualitas hidup dan fungsi belajar.

Produktivitas kerja menurut Tohardi dalam Edy Sutrisno (2012; 100) adalah sikap mental yang selalu mencari perbaikan terhadap apa yang telah ada. Suatu keyakinan bahwa seseorang dapat melakukan pekerjaan lebih baik hari ini daripada hari kemarin dan hari esok lebih baik dari hari ini.Sedangkan Laeha M dan Wexley dalam Tjutju Yuniarsih (2011:47) mengemukakan, produktivitas kerja individu dapat dinilai dari apa yang dilakukan individu, yaitu bagaimana seseorang melaksanakan pekerjaan atau unjuk kerja dalam mencapai hasil yang ditargetkan.

Wayne (2013:21) menyatakan bahwa produktivitas adalah ukuran output barang dan jasa relative terhadap masukan dari tenaga kerja, modal dan peralatan. Sedangkan menurut Schermerhorn (2011:465) produktivitas adalah efisiensi yang merubah masukan menjadi keluaran. Produktivitas sama dengan keluaran (output) dibagi masukan (input).

Berdasar kajian tersebut, maka dapat disintesakan bahwa hakikat produktivitas kerja guru adalah seluruh pencapaian hasil kerja guru dengan mengembangkan kreativitas dalam proses pembelajaran, efektif dan efisien dalam penggunaan waktu, biaya, sarana serta bertanggung jawab atas tercapainya tujuan pendidikan dengan menghasilkan sumber daya manusia yang berkualitas.

\section{Komunikasi Interpersonal}

Komunikasi dilaksanakan oleh setiap individu baik itu komunikasi verbal maupun nonverbal. Dengan berkomunikasi manusia saling bertukar informasi, gagasan, dan pemikiran. Karena itu setiap manusia harus berkomunikasi untuk dapat mencapai tujuannya. Manusia tidak bisa hidup sendirian, ia mengembangkan hubungan dengan orang lain.Robbins dan Judge (2010) mengatakan bahwa komunikasi merupakan cara anggota kelompok dalam berbagi makna dengan orang lain melalui komunikasi lisan, tulis, dan non-verbal. Pada saat mengadakan hubungan (relantionship) itu, terjadilah proses pengolahan pesan secara timbal-balik. Proses ini dikenal sebagai komunikasi interpersonal.

West dan Turner (2010: 33) mengemukakan Interpersonal communication is communication with oneself. It is an internal dialogue and may take place even in the presence of another individual. Interpersonal communication is what goes on inside your head even when you are with someone".

Menurut Luthans (2011: 252,253) bahwa Interpersonal communication represents the middle ground between electronic media and information technology on the extreme and nonverbal communication. In interpersonal communication, the major emphasis on transferring information from one person to another. Communication is looked on as a basic method of effecting behavioral change, and it incorporates the psychological process (perception, learning, and motivation) on the hand and language on the other". Demikian juga pendapat Wood (2013:19), bahwa We can define interpersonal communication as selective, systematic, individual, processual (is an ongoing process) transaction that allow people to reflect and build personal knowledge of one another and create shared meaning". 
Menurut Hardjana (2013:85), komunikasi interpersonal adalah interaksi tatap muka antar dua atau beberapa orang, di mana pengirim dapat menyampaikan pesan secara langsung, dan penerima pesan dapat menerima dan menanggapi secara langsung pula.

Suranto Aw (2011:80-84) menjelaskan dari persektif The 5 Invitable of Effective Communication atau lima hukum komunikasi efektif itu meliputi: Respect, Empaty, Audible, Clarity and Humble. Menurut Suranto Aw yang mengutip dari Devito menggunakan lima sikap positif yang perlu dipertibangkan ketika seseorang merencanakan komunikasi interpersonal. Lima sikap positif tersebut, meliputi keterbukaan, empati, sikap mendukung, sikap positif dan kesetaraan.

Komunikasi interpersonal dianggap paling efektif dalam hal upaya mengubah sikap, pendapat, atau perilaku seseorang, karena sifatnya dialogis, berupa percakapan. Arus balik bersifat langsung. Komunikator mengetahui tanggapan komunikan ketika itu juga, pada saat komunikasi dilancarkan. Komunikator mengetahui pasti apakah komunikasinya itu positif atau negatif, berhasil atau tidak.

Keberhasilan suatu komunikasi interpersonal di sekolah sangat ditentukan oleh cara penyampaian dalam proses komunikasi yang digunakan, guru dan kepala sekolah harus dapat menggunakan pola komunikasi yang sesuai dengan situasi dan tataran komunikasi interpersonal yang dihadapi. Dilain pihak, kesempatan guru-guru untuk mengemukakan usul dan gagasan tentu semakin memperkaya pemikiran baru bagi sekolah itu sendiri.Dari hasil deskripsi konsep yang telah dikemukakan oleh para ahli maka dapat disintesiskan bahwa komunikasi interpersonal merupakan komunikasi yang dilakukan oleh dua orang atau lebih yang memerlukan umpan balik serta berpengaruh pada keberlangsungan hubungan antar individu.

\section{Kepercayaan}

Kepercayaan adalah salah satu sendi dasar tatanan relasi, bahkan George dan Jones (2012:363) mendefinisikan kepercayaan sebagai, "the willingness of one person or group to have faith or confidence in the goodwill of another person, even though this puts them at risk".

Mayer, Davis, dan Schoorman yang dikutip Colquitt, LePine dan Wesson (2011:219) mendefinisikan kepercayaan sebagai, "the willingness to be vulnerable to a trustee based on positive expectations about the trustee's action and intentions". Houston yang dikutip Kreitner (2009: 386) mendefinisikan kepercayaan sebagai, " $a$ belief in the integrity, character or ability of other, is essential if people are to achieve anything together in the long run".

Pengertian kepercayaan menurut Uslu dan Oklay (2015: 81) yang mengartikan kepercayaan organisasi sebagai, "the employee's belief in the competencies of another employees and managers; decisions are made in the organization based on principles of justice, tolerance, ethics, and faith in the processes of implementations".

Reina dan Reina (2008: xv) menyebutkan terdapat tiga jenis kepercayaan, di antaranya: 1) Competence trust relates to individuals' abilities to complete work tasks. 2) Contractual trust, also called trust of character, refers to individuals' attributes such as honesty, consistency, and fairness. And the last, 3) Communication trust refers to the dissemination and accuracy of information. Muhl (2014:16-18) 
menyebutkan dimensi kepercayaan, "there are several operational measures and these are now listed: integrity, bevevolence, concerned, competence, openness, reliability, and intention".

Kepercayaan dapat dipandang dari perspektif organisasi secara internal dan lingkungan eksternal. Kepercayaan juga dapat dikonsep dari berbagai cara, namun kepercayaan sering dihubungkan dengan situasi yang berkaitan dengan konflik personal, ketidakpastian hasil, dan pemecahan masalah.

Kepercayaan dibedakan dalam 2 dimensi yaitu kepercayaan antar sesama pekerja dan antara pekerja dengan atasannya.Kepercayaan interpersonal dinyatakan berhubungan sebab akibat dengan meningkatnya produktifitas kerja.

\section{METODE PENELITIAN}

\section{Tempat dan Waktu Penelitian}

Tempat penelitian adalah Sekolah Dasar yang ada di wilayah Dinas Pendidikan Nasional, Pemuda dan Olahraga Kota Tomohon. Waktu penelitian sekitar 3 (tiga) bulan terhitung sejak akhir Maret sampai dengan awal Mei 2018.

\section{Populasi dan Sampel}

Unit populasi adalah seluruh guru SD di wilayah Dinas Pendidikan Nasional Pemuda dan Olahraga kota Tomohon, yang berjumlah 693 orang. Rincian data unit populasi ini digambarkan sebagai berikut:

Tabel 1. Unit Populasi

\begin{tabular}{|c|l|c|}
\hline No. & Wilayah Dinas Dikpora & Jumlah guru \\
\hline 1 & Tomohon Utara & 180 \\
\hline 2 & Tomohon Tengah & 125 \\
\hline 3 & Tomohon Timur & 77 \\
\hline 4 & Tomohon Barat & 142 \\
\hline 5 & Tomohon Selatan & 169 \\
\hline \multicolumn{2}{|c|}{ Jumlah } & 693 \\
\hline \multicolumn{2}{|c|}{ Sumber : Data Primer (2018) }
\end{tabular}

Sampel penelitian adalah sebagian dari anggota populasi yang ditarik secara random. Ukuran sampel ditentukan dengan menggunakan rumus Taro Yamane (Soekidjo, 2002:92):

$$
\mathrm{n}=\frac{N}{1+N\left(d^{2}\right)} \quad \begin{aligned}
& \text { Keterangan: } \\
& \mathrm{n}=\text { besar sampel } \\
& \mathrm{N}=\text { besar populasi } \\
& \mathrm{d}=\text { presisi (ditetapkan } 10 \% \\
& \text { dengan tingkat kepercayaan 95\%) }
\end{aligned}
$$

Besar sampel adalah:

$\mathrm{n}=\frac{693}{1+693\left(0.1^{2)}\right.}$

$\mathrm{n}=\frac{693}{7.93} \mathrm{n}=87,39$ dibulatkan menjadi 88

Berdasarkan perhitungan di atas, jumlah sampel tiap wilayah akan terdistribusi sebagai berikut: 

1. Tomohon Utara $\frac{180}{693} \times 88=22,85=23$
2. Tomohon Tengah $\frac{125}{693} \times 88=15,86=16$
3. Tomohon Timur $\frac{77}{693} \times 88=9,77=10$
4. Tomohon Barat $\frac{142}{693} \times 88=18,03=18$
5. Tomohon Selatan $\frac{169}{693} \times 88=21,46=21$

Gambaran jumlah anggota sampel per wilayah adalah sebagai berikut:

Tabel 2. Jumlah Sampel

\begin{tabular}{|c|c|c|c|}
\hline No. & Wilayah Dinas Diknaspora & Unit Populasi & Jumlah Sampel \\
\hline 1 & Tomohon Utara & 180 & 23 \\
\hline 2 & Tomohon Tengah & 125 & 16 \\
\hline 3 & Tomohon Timur & 77 & 10 \\
\hline 4 & Tomohon Barat & 142 & 18 \\
\hline 5 & Tomohon Selatan & 169 & 21 \\
\hline \multicolumn{2}{|c|}{ Jumlah } & 693 & 88 \\
\hline
\end{tabular}

Sumber : Data Primer (2018)

\section{Teknik Pengumpulan Data}

Teknik Pengumpulan data yang akan digunakan dalam penelitian ini adalah teknik angket dengan menggunakan skala Likert (Riduwan, 2002:12). Angket adalah teknik pengumpulan data yang dilakukan dengan cara memberikan seperangkat pertanyaan/pernyataan tertulis kepada responden untuk dijawabnya dalam bentuk lembar angket (Riduwan, 2002:24). Alasan peneliti menggunakan angket yaitu karena penelitian ini dilakukan di wilayah kota yang mempunyai luas daerah yang cukup besar dan ada beberapa sekolah yang letaknya berjauhan. Selain itu, dari segi cara memperoleh data akan lebih mudah, faktor biaya dan waktu juga mempengaruhi proses pengumpulan data.

Variabel dalam penelitian ini terbagi dua yaitu variabel bebas (independent) dan variabel terikat (dependent). Variabel bebasnya adalah komunikasi interpersonal (X1) dan kepercayaan (X2) serta sebagai variabel terikatnya adalah produktivitas kerja guru sekolah dasar (Y).

\section{Teknik Analisis Data}

Metode yang akan digunakan dalam penelitian ini adalah metode penelitian kuantitatif untuk meneliti populasi dengan teknik sampling yang diambil secara random. Pengumpulan data menggunakan instrumen penelitian dengan analisis korelasi dan regresi, untuk mengetahui hubungan-hubungan antar variabel. Penelitian ini menggunakan pendekatan ex post facto. Alasan mengapa peneliti menggunakan pendekatan ini, bahwa produktivitas kerja guru yang dimaksud dalam penelitian ini ialah hasil kerja secara optimal yang telah dilakukan guru selama ini, dan akan melihat faktor-faktor apa yang mempengaruhinya selama melaksanakan pekerjaan sebagai pendidik di sekolah dasar khususnya di Kota Tomohon. 


\section{Pengujian Hipotesis \\ Hipotesis Pertama}

Hipotesis pertama yang diuji dalam penelitian ini adalah terdapat yang hubungan signifikan komunikasi interpersonal dengan produktivitas kerja guru sekolah dasar di kota Tomohon. Secara statistik hipotesis tersebut dirumuskan sebagai berikut:

$\mathrm{H}_{0}: \rho=0$ lawan $\mathrm{H}_{1}: \rho \neq 0$

Kriteria pengujian: terima hipotesis $\mathrm{H}_{0}$ jika nilai $p$ (signifikansi hasil perhitungan $=$ sig.) lebih besar dari nilai $\alpha$ (taraf signifikansi yang dipilih $=0.05$ ), sebaliknya tolak hipotesis $\mathrm{H}_{0}$ jika nilai $p$ lebih kecil dari $\alpha$.

\section{Hipotesis Kedua}

Hipotesis kedua yang diuji dalam penelitian ini adalah terdapat hubungan yang signifikan kepercayaan dengan produktivitas kerja guru sekolah dasar di kota Tomohon. Secara statistik hipotesis tersebut dirumuskan sebagai berikut:

$$
\mathrm{H}_{0}: \rho=0 \text { lawan } \quad \mathrm{H}_{1}: \rho \neq 0
$$

Kriteria pengujian: terima hipotesis $\mathrm{H}_{0}$ jika nilai $p$ (signifikansi hasil perhitungan $=$ sig.) lebih besar dari nilai $\alpha$ (taraf signifikansi yang dipilih $=0.05$ ), sebaliknya tolak hipotesis $\mathrm{H}_{0}$ jika nilai $p$ lebih kecil dari $\alpha$.

\section{Hipotesis Ketiga}

Hipotesis ketiga yang diuji dalam penelitian ini adalah terdapat hubungan yang signifikan secara bersama-sama komunikasi interpersonal dan kepercayaan dengan produktivitas kerja guru sekolah dasar di kota Tomohon. Secara statistik hipotesis tersebut dirumuskan sebagai berikut:

$$
\mathrm{H}_{0}: \rho=0 \text { lawan } \quad \mathrm{H}_{1}: \rho \neq 0
$$

Kriteria pengujian: terima hipotesis $\mathrm{H}_{0}$ jika nilai $p$ (signifikansi hasil perhitungan $=$ sig.) lebih besar dari nilai $\alpha$ (taraf signifikansi yang dipilih $=0.05$ ), sebaliknya tolak hipotesis $\mathrm{H}_{0}$ jika nilai $p$ lebih kecil dari $\alpha$.

\section{HASIL PENELITIAN DAN PENELITIAN \\ Hasil Penelitian}

Penelitian ini telah menenuhi uji persyaratan analisis, yakni berdistribusi normal, datanya linier, dan homogen.

Hasil pengujian hipotesis I menunjukkan bahwa terdapat hubungan yang signifikan antara Komunikasi Interpersonal dengan Produktivitas Kerja Guru sekolah dasar di Kota Tomohon. Variasi yang terjadi pada kinerja guru sekolah dasar 13,2\% ditentukan oleh komunikasi interpersonal. Hubungan antara komunikasi interpersonal dengan produktivitas kerja guru sekolah dasar di Kota Tomohon mempunyai arah yang positif, karena hasil analisis menunjukkan persamaan regresi $\hat{Y}=83,597+0,363 X_{1}$. Produktivitas kerja guru sekolah dasar akan terjadi peningkatan rata-rata sebesar 0,363 untuk setiap kenaikan satu skor pada komunikasi interpersonal.

Hasil pengujian hipoesis II menunjukkan bahwa terdapat hubungan antara kepercayaan guru dengan produktivitas kerja guru sekolah dasar di Kota Tomohon. Hasil analisis menunjukan bahwa variasi yang terjadi pada produktivitas kerja guru 
sekolah dasar sebesar 32,5\% ditentukan oleh kepercayaan guru. Hubungan antara kreativitas dengan produktivitas kerja guru sekolah dasar di Kota Tomohon mempunyai arah yang positif, karena hasil

Hasil pengujian hipotesis II menunjukkan bahwa terdapat hubungan antara kepercayaan guru dengan produktivitas kerja guru sekolah dasar di Kota Tomohon. Hasil analisis menunjukan bahwa variasi yang terjadi pada produktivitas kerja guru sekolah dasar sebesar 32,5\% ditentukan oleh kepercayaan guru. Hubungan antara kreativitas dengan produktivitas kerja guru sekolah dasar di Kota Tomohon mempunyai arah yang positif, karena hasil analisis menunjukkan persamaan regresi $\hat{Y}=59,748+$ $0,577 X_{2}$. Produktivitas kerja guru sekolah dasar akan terjadi peningkatan rata-rata sebesar 0,577 untuk setiap kenaikan satu

Gambar 1. Variasi Hubungan Antar Variabel

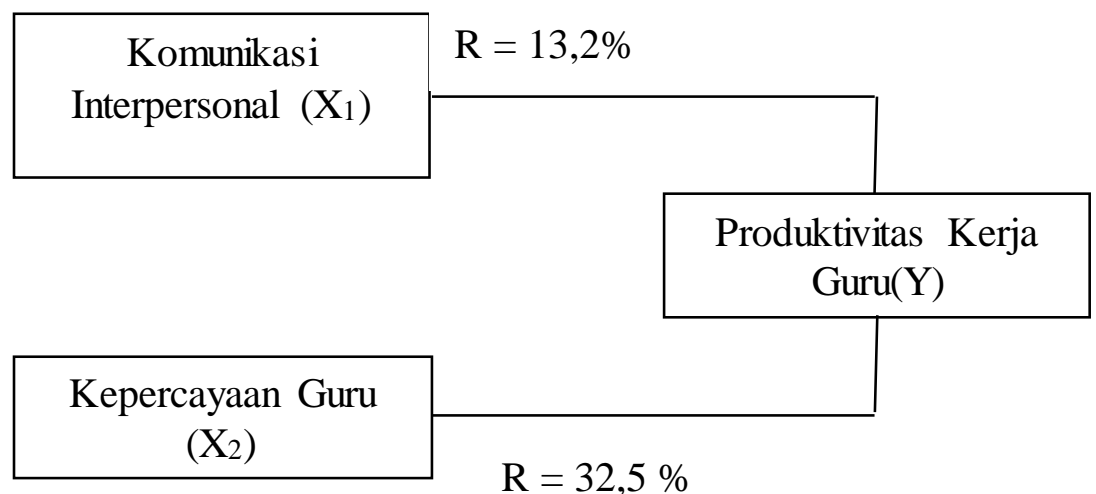

Hasil pengujian hipotesis III menunjukkan bahwa terdapat hubungan yang signifikan secara simultan antara komunikasi interpersonal dan kepercayaan guru dengan produktivitas kerja guru sekolah dasar di Kota Tomohon. Hasil analisis menyatakan bahwa 33,4\% variasi yang terjadi pada produktivitas kerja guru sekolah dasar di Kota Tomohon ditentukan secara bersama-sama oleh komunikasi interpersional dan kepercayaan guru. Hasil pengujian diperoleh persamaan regresi $\hat{Y}=$ $61,509+0,044 \mathrm{X}_{1}+0,607 \mathrm{X}_{2}$. Persamaan regresi ini menunjukkan arah positif untuk variabel Komunikasi Interpersonal $\left(\mathrm{X}_{1}\right)$ yang berarti kenaikan variabel Komunikasi Interpersonal $\left(\mathrm{X}_{1}\right)$ dengan mengontrol Kepercayaan Guru $\left(\mathrm{X}_{2}\right)$ akan mengakibatkan kenaikan pada Produktivitas Kerja Guru (Y). Begitu pula bila kita menurunkan variabel $\mathrm{X}_{1}$ dengan mengontrol $\mathrm{X}_{2}$ akan mengakibatkan penurunan pada variabel $\mathrm{Y}$.

Hal yang sama terjadi pada variabel Kepercayaan Guru $\left(\mathrm{X}_{2}\right)$. Persamaan regresi diatas menunjukkan arah positif untuk variabel Kepercayaan Guru $\left(\mathrm{X}_{2}\right)$, ini berarti bahwa setiap kenaikan atau penurunan variabel Kepercayaan Guru $\left(\mathrm{X}_{2}\right)$ dengan mengontrol variabel Komunikasi Interpersonal $\left(\mathrm{X}_{1}\right)$, akan mengakibatkan terjadinya kenaikan atau penurunan pada variabel Produktivitas Kerja Guru (Y). 


\section{Gambar 2.Bagan Hasil Analisis Korelasi Ganda}

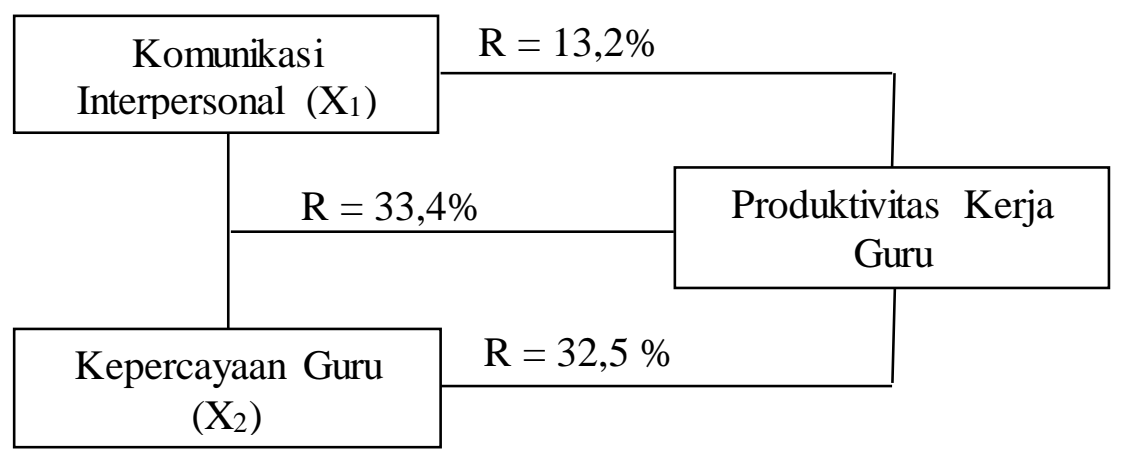

Peningkatan yang terjadi pada produktivitas kerja guru sekolah dasar yang disebabkan oleh adanya peningkatan pada variabel komunikasi interpersonal sejalan dengan pendapat West dan Turner, Luthans, serta Wood. Menurut Richard West\& Lynn H. Turner (2010:10) komunikasi interpersonal ialah: "we define interpersonal communication as the process of message transaction between people to create a sustain share meaning. there are critical components embeded in this definition: process, message exchange, and shared meaning”. Luthans (2011:252,253) menjelaskan bahwa Interpersonal communication represents the middle ground between electronic media and information technology on the extreme and nonverbal communication. In interpersonal communication, the major emphasis on transferring information from one person to another. Communication is looked on as a basic method of effecting behavioral change, and it incorporates the psychological process (perception, learning, and motivation) on the hand and language on the other". Demikian juga pendapat Wood (2013:19), bahwa We can define interpersonal communication as selective, systematic, individual, processual (is an ongoing process) transaction that allow people to reflect and build personal knowledge of one another and create shared meaning".

Keberhasilan suatu komunikasi interpersonal di sekolah sangat ditentukan oleh cara penyampaian dalam proses komunikasi yang digunakan, guru dan kepala sekolah harus dapat menggunakan pola komunikasi yang sesuai dengan situasi dan tataran komunikasi interpersonal yang dihadapi. Dilain pihak, kesempatan guru-guru untuk mengemukakan usul dan gagasan tentu semakin memperkaya pemikiran baru bagi sekolah itu sendiri.Dari hasil deskripsi konsep yang telah dikemukakan oleh para ahli maka dapat disintesiskan bahwa komunikasi interpersonal merupakan komunikasi yang dilakukan oleh dua orang atau lebih yang memerlukan umpan balik serta berpengaruh pada keberlangsungan hubungan antar individu.

Peningkatan yang terjadi pada produktivitas kerja guru sekolah dasar yang disebabkan oleh adanya peningkatan pada variabel kepercayaan guru, sejalan dengan pendapat Uslu dan Oklay (2015: 81) yang mengartikan kepercayaan organisasi sebagai, "the employee's belief in the competencies of another employees and managers; decisions are made in the organization based on principles of justice, tolerance, ethics, and faith in the processes of implementations". Menurut Reina dan 
Reina (2008: xv) menyebutkan terdapat tiga jenis kepercayaan, di antaranya: 1) Competence trust relates to individuals' abilities to complete work tasks. 2) Contractual trust, also called trust of character, refers to individuals' attributes such as honesty, consistency, and fairness. And the last, 3) Communication trust refers to the dissemination and accuracy of information. Kepercayaan dibedakan dalam 2 dimensi yaitu kepercayaan interpersonal (antar sesama pekerja dan antara pekerja dengan atasannya) dan sistem kepercayaan (antara pekerja dengan organisasi secara keseluruhan). Dikotomi tersebut menyatakan bahwa tingkat kepercayaan seorang individu pada atasannya berbeda dengan pada organisasi secara keseluruhan. Kepercayaan interpersonal dalam organisasi dibangun dengan tujuan untuk meningkatkan kinerja individu. Jadi kepercayaan interpersonal berhubungan sebab akibat dengan meningkatnya produktifitas kerja guru.

Kepercayaan yang telah terbangun dapat mendukung pemenuhan harapan guru dalam bekerja. Kepercayaan terjadi pada orang-orang yang memiliki perasaan nyaman terhadap jabatan, rekan kerja, pimpinan, dan lingkungan kerja. Ketika seorang guru merasa yakin bahwa kemampuan dan kapasitas dirinya dihargai, maka inisiatif dan kreatifitasnya akan tumbuh. Jika kepercayaan telah terbentuk, maka produktivitas kerja akan tumbuh dan meningkat. Hal ini membuat guru dapat menjalankan tugas dan tanggung jawabnya dengan baik. Oleh karena itu, kepercayaan yang dimiliki guru berkaitan erat dengan produktivitas kerja guru.

\section{KESIMPULAN DAN SARAN Kesimpulan}

Berdasarkan hasil analisis data dalam penelitian ini dapat ditarik beberapa kesimpulan sebagai berikut:

1. Terdapat hubungan yang berarti antara komunikasi interpersonal dengan produktivitas kerja guru sekolah dasar di kota Tomohon. Arah hubungan positif, besar hubungan 0,363 atau $13,2 \%$ produktivitas kerja guru sekolah dasar di kota Tomohon ditentukan oleh variabel komunikasi interpersonal.

2. Terdapat hubungan yang berarti antara kepercayaan guru dengan produktivitas kerja guru sekolah dasar di kota Tomohon. Arah hubungan positif, besar hubungan 0,577 atau sekitar $32,5 \%$ produktivitas kerja guru sekolah dasar di kota Tomohon ditentukan oleh variabel kepercayaan guru.

3. Terdapat hubungan yang berarti antara komunikasi interpersonal dan kepercayaan guru dengan produktivitas kerja guru sekolah dasar di kota Tomohon. Arah hubungan positif, besar hubungan 0,578 atau sekitar 33,4\% produktivitas kerja guru sekolah dasar di kota Tomohon ditentukan secara simultan oleh variabel komunikasi interpesersonal dan kepercayaan guru.

\section{Saran}

Hasil penelitian menunjukkan betapa kuatnya hubungan antara komunikasi interpersonal dan kepercayaan guru dengan produktivitas kerja guru sekolah dasar di kota Tomohon. Karenanya peneliti mengajukan beberapa saran, sebagai berikut:

1. Besarnya kontribusi komunikasi interpersonal pada produktivitas kerja guru sekolah dasar di kota Tomohon perlu mendapat perhatian yang lebih dalam arti kominikasi 
interpersonal harus mendapat perhatian dari pimpinan untuk terus diadakan pembinaan dan pengembangan potensi guru. Caranya dengan membangun komunikasi secara intensif baik kepala sekolah dengan guru maupun guru dengan teman sejawat.

2. Kepercayaan guru memberi kontribusi pada produktivitas kerja guru sekolah dasar di kota Tomohon. Semakin baik kepercayaan yang diberikan pada guru, akan memotivasi guru bekerja lebih baik. Dalam hal ini pimpinan sekolah dan/atau instansi yang terkait sebaiknya memperhatikan dan menghargai kerja baik dari guru dengan memberi kepercayaan.

3. Komunikasi interpersonal dan kepercayaan guru secara simultan memberi kontribusi sebesar 33,4\% terhadap produktivitas kerja guru sekolah dasar di kota Tomohon. Demikian signifikannya kontribusi tersebut tentu tidak bisa diabaikan, karena akan berdampak besar pada produktivitas kerja guru. Karena itu disarankan agar pimpinan sekolah dan intansi terkait melakukan perbaikan, baik menyangkut kominikasi interpersonal gurunya maupun menyangkut kepercayaan pada gurunya.

\section{DAFTAR PUSTAKA}

Colquitt, Jason A, Jeffery A. Lepine \& Michael J. Wesson. 2011. Organizational Behavior: Improving Performance and Commitment in the Workplace. New York: McGraw-Hill.

George, Jennifer M \& Gareth R. Jones. 2012. Understanding and Managing Organizational Behavior $6^{\text {th }}$ Edition. Upper Saddle River: Prentice Hall.

Hardjana, Agus M. 2013. Komunikasi Intrapersonal dan Interpersonal. Yogyakarta: Kanisius.

Kreitner, Robert. 2009. Management Eleventh Edition. New York: Houghton Mifflin Harcourt Publishing Company.

Kreitner dan Kinicki. 2009. Organizational Behavior. New York : McGraw Hil.

Luthans, Fred. 2011. Organizational Behavior. New York: Congress Cataloging-inPublication Data.

Muchdarsyah, S. 2008. Produktivitas: Apa dan Bagaimana. Jakarta: Bumi Aksara.

Muhl, Johannes Karl. 2014. Organizational Trust: Measurement, Impact, and the Role of Management Accountants. Switzerland: Springer International Publishing.

Reina, D.S \& M. Reina. 2008. Trust and Betrayal in the Workplace: Building Effective Relationships in Your Organization. California: Berrett-Koehler Publishers.

Robbin,S.P \& Timothy A.J. 2010. Organizational Behavior (4th Edition). New Jersey, NJ: Pearson Education Inc.

Schermerhorn, John R. 2012. Organizational Behavior. United States of America: Quad Graphics.

Sedarmayanti. 2009. Sumber Daya Manusia dan Produktivitas Kerja. Bandung: Sumbersari Indah.

Soekidjo, N. 2002, Metodologi Penelitian Kesehatan, Rineke Cipta, Jakarta.

Suranto Aw. 2011. Komunikasi Interpersonal. Yogyakarta: Graha Ilmu.

Sutrisno, Edy. 2012. Manajemen Sumber Daya Manusia. Jakarta: Kencana Prenada Media Group. 
Trivedi, Madhukar H. 2013. Increase in Work Productivity of Depresed Individuals with Improvement in Depressive Symptom Severity. Am J Psychiatry.

Umar, Husein. 2008. Desain Penelitian MSDM dan Perilaku Karyawan: Paradigma Positivistik dan Berbasis Pemecahan Masalah. Jakarta: PT. Grafindo Persada.

Uslu, Fatma \& Erdem Oklay. 2015. Leadership and Organizational Outcomes: MetaAnalysis of Empirical Studies. Engin Karadag (Ed.). Switzerland: Springer International Publishing.

Wayne, Cascio F. 2013. Managing Human Resources: Produktivity, Quality of Work life, Profits. New York: McGraw-Hill International Edition.

West Rechard \& Lynn H. Turner. 2010. Intriducing Communication Theory. New York Printed in Singapore.

Wood Julia T. 2013. Interpersonal Cummunication: Everyday Encounters. Boston: Wadsworth.

Yuniarsih, Tjutju. 2011. Manajemen Sumber Daya Manusia. Bandung: Alfabeta 